\title{
SPECIFICATION OF AN INTERNET ARCHITECTURE OF THINGS FOR A GRAIN TRACEABILITY FRAMEWORK
}

\author{
Luma Alves Lopes and Maria Salete Marcon Gomes Vaz \\ Programa de Pós-Graduação em Computação Aplicada - Universidade Estadual de Ponta Grossa \\ Av. General Carlos Cavalcanti, 4748. CEP 84.030-900 - Ponta Grossa, Paraná, Brazil
}

\begin{abstract}
Obtaining correct and timely information is important for the agricultural area because it enables safer activities to be carried out in a strategic and operational context. Because data represents the main support for decision making, an efficient traceability process must ensure that the data to be tracked is in line with reality. With Internet of Things and real-time data availability, you can have accurate and reliable decision-making by enabling smart tools to collect data automatically and send it to the traceability system. The purpose of this paperwork is to specify an Internet Architecture of Things for a grain traceability framework. The proposed model considers the specifications of the RastroGrão framework and the Internet reference of Things of the Internet of Things Architecture project. The model obtained reduces human error and provides food safety.
\end{abstract}

\section{KEYWORDS}

Food Safety, Framework, Production Management

\section{INTRODUCTION}

Obtaining accurate information in a timely manner is important for the agricultural area because it enables safer activities to be carried out in a strategic and operational context.

Because data represents the main support for decision making, an efficient traceability process must ensure that the data to be tracked is in line with reality. Some traceability models do not address automatic data collection, and once the data is entered manually, they can raise questions about the quality of the system and the data to be traced.

With Internet of Things (IoT) and real-time data availability, accurate and reliable decision-making can be achieved by enabling intelligent tools to automatically collect data and send it to the traceability system.

Vaz (2014) specified the RastroGrão framework in order to track any type of grain, through Product management, Production phases and Attributes to be tracked. The purpose of this article is to present an extension of the RastroGrão in order to guarantee the quality of the Attribute to be traced by obtaining the Internet of Things data.

\section{INTERNET OF THINGS AND TRACEABILITY}

In the Internet of Things, computers have the ability to obtain information without human interference, using technologies that allow them to observe, identify and understand the world (ASHTON, 2009). In the IoT environment there are objects such as Radio Frequency Identification (RFID), sensors, actuators, cell phones and so on. which, through addressing mechanisms, such as the Internet, interact and cooperate with each other to achieve some objective (GIUSTO et al, 2010).

The definition of IoT, also known as Internet of Everything (IoE) (HUSSAIN, 2017), directs to a communication network, involving processes, society, phenomena, data and objects. This concept makes it 
possible, from a data and object viewpoint, for data to be transformed into correct information, and once it is delivered to devices and interconnected objects at the right time, allows for intelligent decision making.

Based on these concepts of IoT, one can have interconnected sensors creating a Network of Wireless Sensors - RSSF (ALABA et al, 2017). An RSSF corresponds to the use of geographically distributed sensors in an environment capable of monitoring the environment, collecting and processing data, and then sending them to one or more points of interest through wireless communication (DWIVEDI, VYAS, 2011).

In this sense, IoT is important for the economy and for society (LI et al, 2012) and has the potential for the development of intelligent applications in various fields, such as industry, smart cities, and health and well- being (BORGIA, 2014).

The field of industry can be subdivided into three areas: agriculture and livestock, logistics and product management and industrial process. In smart cities we have mobility and tourism, smart grids, buildings and intelligent houses. Finally, in health and well-being it can be subdivided into two areas: public health and the environment, medicine and health

In agriculture, some examples of IoT application are in climate and soil monitoring, irrigation optimization, greenhouse control, greenhouse control and the traceability of the production chain (TZOUNIS et al, 2017). In traceability, IoT objects can monitor the entire production chain, collecting data from sensors, drones, satellite images, automated machines, among others, from planting and/or seeding to delivery of the product to the final consumer.

In this way, it has benefited consumers by allowing them, for example, to access additional information about products, in addition to manufacturers, by increasing the number of products that use identification technologies such as RFID tags and smart sensors, enabling products to be monitored and traced throughout their life cycles.

The traceability can be understood as the ability to track, track and identify only one product at all stages of production, processing and distribution (DERRICK and DILON, 2004). Through access to records, information and data handling at any point in the production chain, traceability ensures product quality and consumer protection by enabling the elimination of defective food products and promoting research into the causes of the problems (BADIA -MELIS et al, 2015).

A quality-driven traceability system, as well as location and identification data, is concerned with relevant data on product quality such as humidity and temperature, which are captured by intelligent tools such as sensors to control and manage the flow of products in the production chain (SCHEER, 2006).

Therefore, it can be highlighted that an efficient traceability system, also presented by Gazolla et al (2017), aims to guarantee food safety, origin control and product quality, consumer right to information, and uses technological innovations to improve the organization of production chains. The ISO (2007) stresses that a traceability system should consider the existence of other operating and management systems present in an organization.

Vaz (2014) specified the traceability framework, RastroGrão, in order to track any type of grain, through the management of Product, Production Phases and Attributes to be tracked in each production phase. The access to the system is done through the internet, allowing the information to be accessed and customized by all agents of the chain since the structure of the framework divided into five modules allows adaptation to the rules of each agribusiness. Mantuani (2017) carried out the extension of RastroGrão with the concepts of geoinformation. This enabled Module V to provide information on the location of the products to be traced, allowing the geo-traceability process to be integrated during all stages of traceability.

\section{RESEARCH METHODOLOGY}

The proposed approach for the development of this research is characterized as being qualitative. The bibliographic research was used to acquire the knowledge and extraction of data from the context of IoT and traceability.

The grain traceability structure will be used as proposed by Vaz (2014) and consider the specifications of the reference model for the Internet of Things proposed by the Internet of Things Architecture project. The IoT-A reference model was proposed to describe the IoT including: a domain model, which describes the concepts belonging to an area of interest; the information model, responsible for describing the data to be processed; and the functional model, which describes the interaction between objects (WALEWSKI et al, 2013). With regard to the nature and objectives of the research, this work is characterized by being applied and descriptive, as it seeks to present an IoT specification in a traceability framework. 


\section{INTERNET OF THINGS IN THE TRACEABILITY FRAMEWORK}

To understand the proposed model, it is necessary to describe what is meant by physical entities and devices. Thus, physical entities are the lots, products, fields and other assets of interest, such as trucks or silos, which may be grain-producing property, or the data management company.

The devices can be of the type sensors, actuators or tags. Sensors are responsible for monitoring the physical environment, while actuators modify the environment according to commands received by sensors or by the traceability system. The tags are identifiers that contain data on a lot, besides being an element of RFID tags.

In the proposed architecture, presented in Figure 1, physical entities are physically linked to microcontrolling devices, whereas these devices connect to the traceability framework using wireless connectivity.

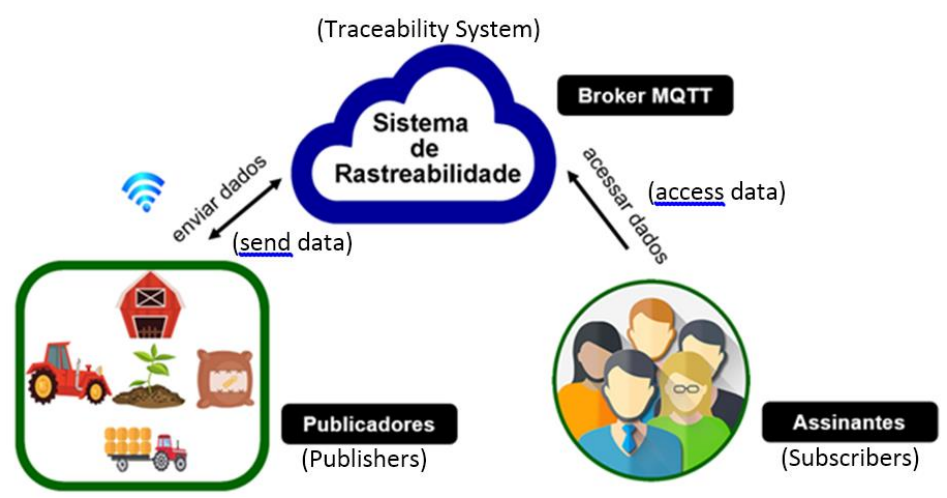

Figure 1. IoT Architecture for the Framework Source: The Authors.

The exchange of messages between the devices and the grain traceability framework is performed through the MQTT protocol. Because the MQTT protocol uses the publish / subscribe paradigm, where messages sent by publishers are processed on a specific topic, the traceability framework itself will act as a broker, responsible for receiving and managing the messages that will be sent. In this perspective, microcontrollers that capture data and/or information about a phenomenon of interest, are called publishers, while the users, registered to manipulate and manage the data that should be tracked by the system, are called subscribers.

The traceability framework, hosted on a web server allows application users to access, in real time, two IoT services. The first is the monitoring of a physical entity, for example through the use of identification tags. The second concerns the management of the attribute to be traced during the stages of the grain production chain.

The management of the traceability structure, of any type of grain, is performed through the management of Products, Phases and Attributes (or Data) to be traced. To manage the attribute to be traced during the stages of the grain production chain, the Vaz (2014) traceability structure is extended with the insertion of the resource management. These resources assist in collecting the data on the traced attributes (Figure 2).

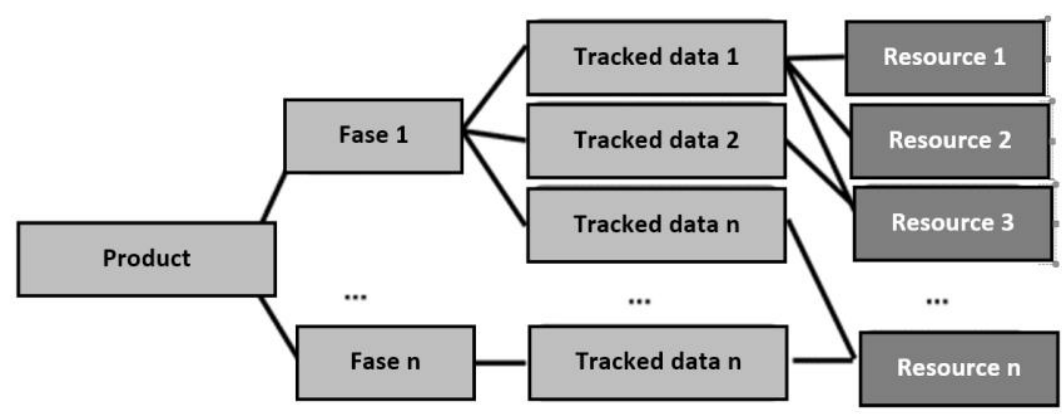

Figure 2. Framework custimization estructure Source: The Authors. 
The resources, which are a means of automatically capturing the data to be traced, can be made available by devices or by the network. In case of use of resources of the network, these can refer to the cases where the connection with other software is made, or if it uses the resources of the framework itself.

As security is an important requirement in a traceability system, it is necessary for the framework to perform device management. Thus, only devices authenticated in the system can update a data/ information about an attribute to be traced in order to maintain the integrity of the system and the stored data.

In addition, before updating a data in the system, it must be verified that the communication channel between the devices and the framework is active. If a communication failure is detected, the device must have mechanisms to store the data in the system as soon as possible.

\section{CONCLUSION}

This work presented the integration of an Internet Architecture of Things into a grain traceability framework.

Among the advantages of using the model is the reduction of human error and food safety, since as data is being collected by devices, it is avoided the erroneous filling of forms, either by carelessness or omission of information. In this way, the obtained framework can have quality data in all the stages of manufacture of a product.

As the focus is on the framework and considering that each data can be traced using an intelligent tool, in practice, this can lead to financial costs according to the number of devices used by each agent in the production chain. As future work, it is intended to validate the proposed structure in the traceability of soy, so that it is possible to collect data during all phases of the production process.

\section{REFERENCES}

Alaba, F. A. et al, 2017. Internet of Things security: A survey. Journal of Network and Computer Applications, 88, pp. 10-28.

Ashton, K., 2009. That 'Internet of Things' Thing. RFID Journal. s/n.

Badia-Melis, R. et al., 2015. Food traceability: New trends and recent advances. A review. Food Control, 57, pp.393-401.

Borgia, E., 2014. The Internet of Things vision: Key features, applications and open issues. Journal of Computer Communications, 54(1), 1-31.

Derrick, S; Dilon, M., 2004. A Guide to Traceability within the Fish Industry. Publisher Eurofish, pp.78.

Dwivedi, A. K.; Vyas, O. P., 2011. Wireless Sensor Network: At a Glance. Recent Advances in Wireless Communications and Networks, Jia-Chin Lin, IntechOpen, pp.299-326.

Gazolla et al., 2017. Rastreabilidade e variabilidade espacial da qualidade fisiológica de sementes soja em campo de produção. Revista Brasileira de Tecnologia Agropecuária. 1(1), pp.65-73.

Giusto, D. et al. 2010. The Internet of Things: 20th Tyrrhenian Workshop on Digital Communication. Springer, New York.

ISO 22005, 2007. Traceability in the feed and food chain - General principles and basic requirements for system design and implementation, s.l.: ISO.

Li, Y. et al., 2012. Towards a theoretical framework of strategic decision, supporting capability and information sharing under the context of Internet of Things. Information Technology and Management, 13(4), pp.205-216.

Mantuani, S. R., 2017. Integração de geoinformação no framework de rastreabilidade de grãos. MS diss Ponta Grossa: Universidade Estadual de Ponta Grossa, Setor de Ciências Agrárias e de Tecnologia.

Scheer, F. P., 2006. Optimizing supply chains using traceability systems. In: Smith, I.; Furness, A. Improvising traceability in food processing and distribution. Woolhead publishing, Cambridge, UK, pp.52-64.

Tzounis, A., et al., 2017. Internet of Things in Agriculture, Recent Advances and Future Challenges. Biosystems Engineering, 164, pp.31-48.

Vaz, M. C. S., 2014. Especificação de um framework para rastreabilidade da cadeia produtiva de grãos. MS diss. Ponta Grossa: Universidade Estadual de Ponta Grossa, Setor de Ciências Agrárias e de Tecnologia.

Walewski, J. et al., 2013. Internet-of-Things Architecture IoT-A. Project Deliverable D1.2 - Initial Architectural Reference Model for IoT. 